\title{
Synthesis of $\mathrm{BiNbO}_{4}$ by the Flux Method
}

\author{
Yuki Maruyama, Chihiro Izawa, and Tomoaki Watanabe \\ Department of Applied Chemistry, School of Science and Technology, Meiji University, Kanagawa 214-8571, Japan \\ Correspondence should be addressed to Tomoaki Watanabe, tomowata@meiji.ac.jp
}

Received 2 July 2012; Accepted 12 August 2012

Academic Editors: A. Dias and G. M. do Nascimento

Copyright ( $) 2012$ Yuki Maruyama et al. This is an open access article distributed under the Creative Commons Attribution License, which permits unrestricted use, distribution, and reproduction in any medium, provided the original work is properly cited.

\begin{abstract}
$\mathrm{BiNbO}_{4}$ has been successfully synthesized using $\mathrm{Bi}_{2} \mathrm{O}_{3}-\mathrm{B}_{2} \mathrm{O}_{3}$ eutectic flux. In particular, we succeeded in synthesizing a lowtemperature-phase $\mathrm{BiNbO}_{4}$ crystal $\left(\alpha-\mathrm{BiNbO}_{4}\right)$ at $1073 \mathrm{~K}$ as well as high-temperature-phase $\mathrm{BiNbO}_{4}$ crystal $\left(\beta-\mathrm{BiNbO}_{4}\right)$. The morphology of $\alpha-\mathrm{BiNbO}_{4}$ and $\beta-\mathrm{BiNbO}_{4}$ particles prepared by the flux method is a euhedral crystal. In contrast, the morphology of particles prepared by solid state reaction differs: $\alpha-\mathrm{BiNbO}_{4}$ is aggregated and $\beta-\mathrm{BiNbO}_{4}$ is necked. Ultraviolet-visible diffuse reflectance spectra indicate that the absorption edge is at a longer wavelength for $\beta-\mathrm{BiNbO}_{4}$ than for $\alpha-\mathrm{BiNbO}_{4}$ with $\beta-\mathrm{BiNbO}$ absorbing light of wavelengths up to nearly $400 \mathrm{~nm}$.
\end{abstract}

\section{Introduction}

Since the photocatalytic reaction of $\mathrm{TiO}_{2}$ was reported in the 1970s, many oxide photocatalysts have been studied [1]. The electrons of oxide photocatalysts are excited from the valence band to the conduction band by the absorption of light with energy equal to or greater than the band gap, resulting in the generation of electrons and holes that then undergo redox reaction [2]. This behavior has been linked to the decomposition of organic substances $[3,4]$.

In light of our planet's current serious energy problems, oxide photocatalysts that possess band gaps near that required to split water are of particular interest [5]. Among candidate photocatalysts, $\mathrm{BiNbO}_{4}$ seems especially promising for the following reasons: (1) it exhibits higher photocatalytic activity for $\mathrm{H}_{2}$ evolution than $\mathrm{TiO}_{2}$ [6], (2) it undergoes a phase transition from low-temperature orthorhombic to high-temperature triclinic at $1293 \mathrm{~K}$ [7-9], and (3) its low-temperature phase exhibits higher photocatalytic activity than its high-temperature phase [10-14].

To date, the principal method for synthesizing $\mathrm{BiNbO}_{4}$ 's low-temperature phase has been solid state reaction. Among the few reported alternative methods, a method using lowtemperature liquid-phase reaction has been shown to produce a product that is more crystalline than that produced by solid state reaction $[15,16]$. In addition, a method using
BiOF flux has been shown to produce low-temperaturephase $\mathrm{BiNbO}_{4}$ [17]. However, in the latter case, mechanical separation of a product from flux has been difficult.

In this study, we solved the problem of separating a product from flux in the second method cited above by using a new flux: $\mathrm{Bi}_{2} \mathrm{O}_{3}-\mathrm{B}_{2} \mathrm{O}_{3}$ eutectic flux. $\mathrm{BiNbO}_{4}$ so prepared exhibits higher crystallinity than that obtained by solid state reaction.

\section{Experimental}

$\alpha-\mathrm{BiNbO}_{4}$ and $\beta$ - $\mathrm{BiNbO}_{4}$ were prepared by two ways- the flux method and solid state reaction-from the following starting materials: $\mathrm{Bi}_{2} \mathrm{O}_{3}$ (Kojundo Chemical Laboratory Co., Ltd., Japan), $\mathrm{Nb}_{2} \mathrm{O}_{5}$ (Kojundo Chemical Laboratory Co., Ltd., Japan), and $\mathrm{B}_{2} \mathrm{O}_{3}$ (Wako Pure Chemical Industries Ltd., Japan).

For preparation by the flux method, the starting reactants were mixed at a molar ratio of $\mathrm{Bi}_{2} \mathrm{O}_{3}: \mathrm{Nb}_{2} \mathrm{O}_{5}: \mathrm{B}_{2} \mathrm{O}_{3}=$ $11: 11: 9$. The mixture was heated in an alumina boat at $10 \mathrm{~K} / \mathrm{min}$ from room temperature to $1073 \mathrm{~K}$ or $1473 \mathrm{~K}$ in an electric tube furnace, held at $1073 \mathrm{~K}$ or $1473 \mathrm{~K}$ for $10 \mathrm{~h}$, and allowed to cool naturally to room temperature. The product was separated from flux by washing with $2 \mathrm{M} \mathrm{HNO}_{3}$ in an ultrasonic bath for $2 \mathrm{~h}$ and then dried at $353 \mathrm{~K}$. 


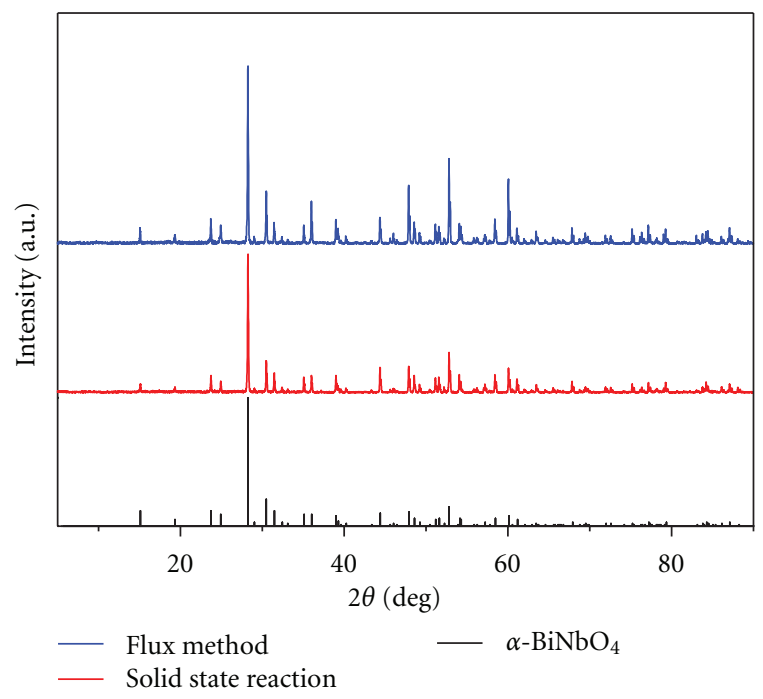

FIGURE 1: XRD patterns of $\mathrm{BiNbO}_{4}$ prepared at a low temperature by the flux method $(1073 \mathrm{~K}, 10 \mathrm{~h})$ and solid state reaction (1173 K, $\left.24 \mathrm{~h}\right)$. For comparison, the standard XRD pattern for ICDD data 01-082-0348 is also shown.

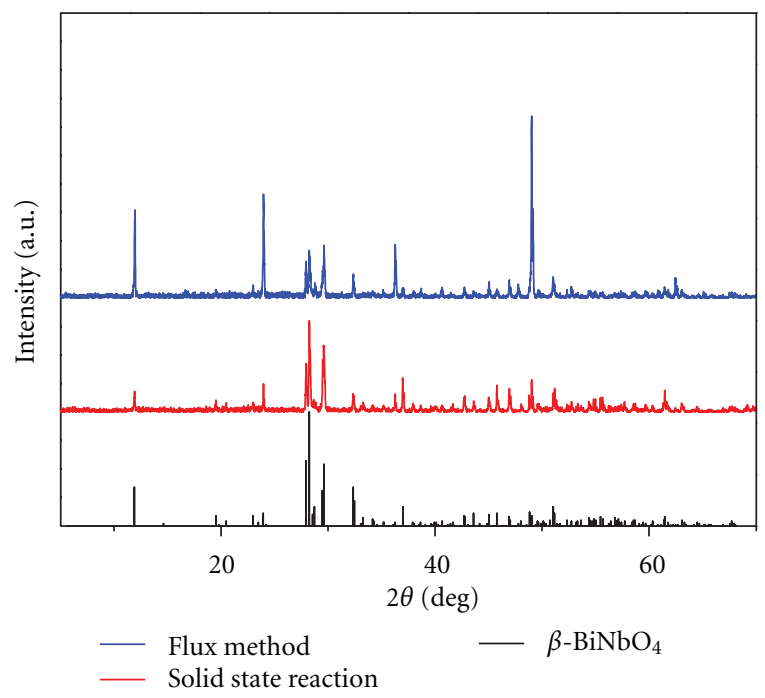

FIGURE 2: $\mathrm{XRD}$ patterns of $\mathrm{BiNbO}_{4}$ prepared at a high temperature by the flux method $(1473 \mathrm{~K}, 10 \mathrm{~h})$ and solid state reaction (1473 $\left.\mathrm{K}, 24 \mathrm{~h}\right)$, For comparison, the standard XRD pattern for ICDD data 01-071-1518 is also shown.

For preparation by solid state reaction, starting reactants $\mathrm{Bi}_{2} \mathrm{O}_{3}$ and $\mathrm{Nb}_{2} \mathrm{O}_{5}$ were mixed in an appropriate stoichiometric ratio for $30 \mathrm{~min}$ by in an agate mortar. The mixture was heated in an alumina boat at $10 \mathrm{~K} / \mathrm{min}$ from room temperature to $973 \mathrm{~K}$ for $3 \mathrm{~h}$ in an electric tube furnace, cooled to room temperature, removed from the furnace, remixed for $30 \mathrm{~min}$ in the agate mortar, and then heated in the alumina boat at $10 \mathrm{~K} / \mathrm{min}$ from room temperature to $1173 \mathrm{~K}$ or $1473 \mathrm{~K}$ for $24 \mathrm{~h}$ in the furnace.

The crystal structures of the products were determined by X-ray diffraction (XRD, Rigaku RINT-2200 diffractometer using $\mathrm{CuK} \alpha$ radiation and operating at $40 \mathrm{kV}$ and $40 \mathrm{~mA}$ ). Product morphology was observed by scanning electron microscopy (SEM, Hitachi S-5200). Moreover, UVVis diffuse reflectance spectra were obtained by UV-Vis spectrophotometry (JASCO-550).

\section{Results and Discussion}

The transition of $\mathrm{BiNbO}_{4}$ from the low-temperature orthorhombic phase to the high-temperature triclinic phase is well known to occur at $1293 \mathrm{~K}$. An eutectic point is at $923 \mathrm{~K}$ at a molar ratio of $\mathrm{Bi}_{2} \mathrm{O}_{3}: \mathrm{B}_{2} \mathrm{O}_{3}=11: 9$ [18]. Figure 1 shows the XRD patterns for the products prepared at a low temperature by the flux method using $\mathrm{Bi}_{2} \mathrm{O}_{3}-\mathrm{B}_{2} \mathrm{O}_{3}$ eutectic flux at $1073 \mathrm{~K}$ and by solid state reaction at $1173 \mathrm{~K}$. These 


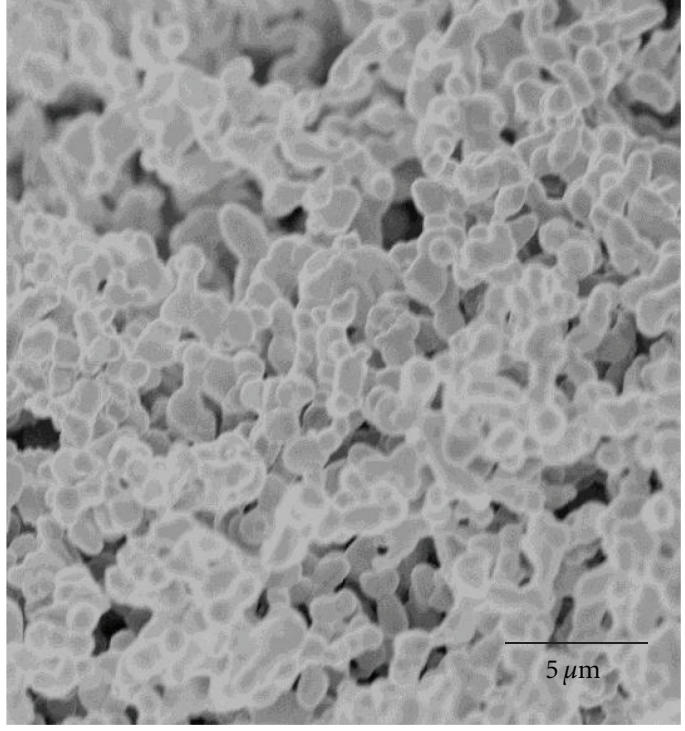

(a)

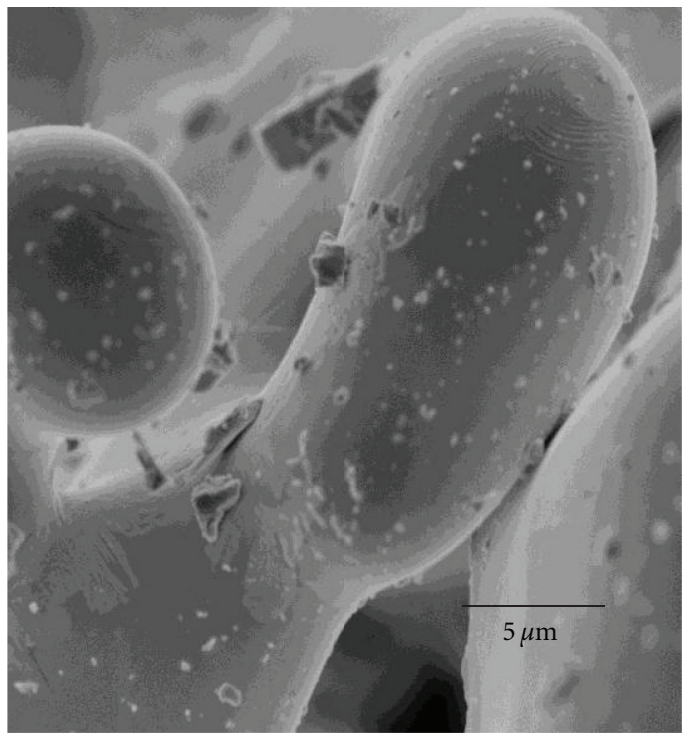

(c)

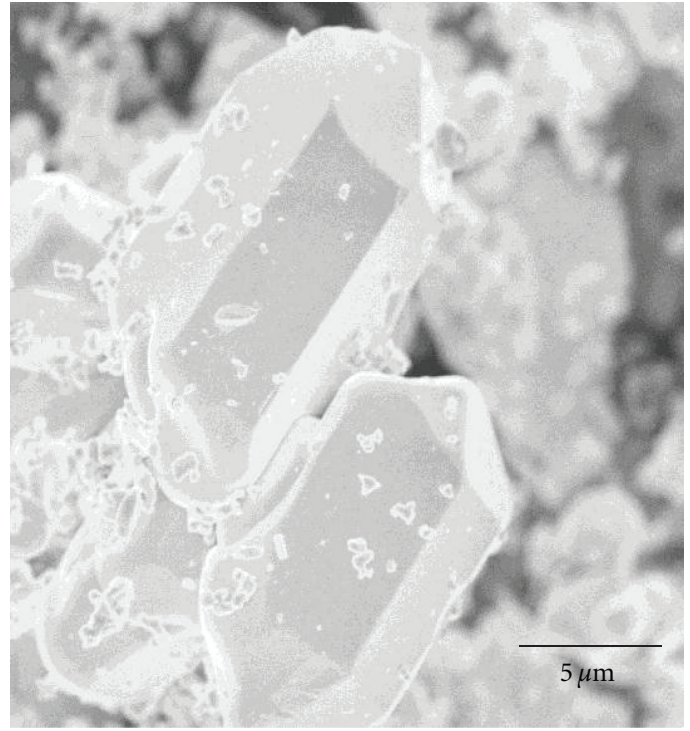

(b)

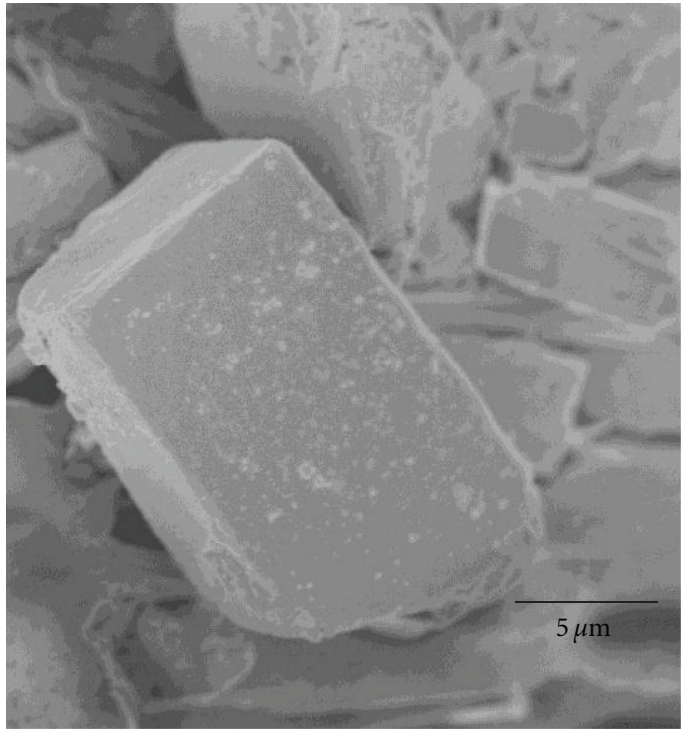

(d)

FIgURE 3: SEM images of $\mathrm{BiNbO}_{4}$ prepared by the flux method and solid state reaction at high and low temperatures: (a) by solid state reaction $(1173 \mathrm{~K}, 24 \mathrm{~h})$, (b) by the flux method $(1073 \mathrm{~K}, 10 \mathrm{~h})$, (c) by solid state reaction $(1473 \mathrm{~K}, 24 \mathrm{~h})$, and (d) by the flux method ( $1473 \mathrm{~K}$, $10 \mathrm{~h})$.

patterns agree with the pattern for $\mathrm{BiNbO}_{4}$ reported in ICDD data 01-082-0348 [17]. Similarly, Figure 2 shows the XRD patterns for the product prepared at a high temperature by the same two ways: flux method using $\mathrm{Bi}_{2} \mathrm{O}_{3}-\mathrm{B}_{2} \mathrm{O}_{3}$ eutectic flux at $1473 \mathrm{~K}$ and solid state reaction at $1473 \mathrm{~K}$. These patterns agree with the pattern for $\mathrm{BiNbO}_{4}$ reported in ICDD data 01-071-1518 [19]. Moreover, diffraction intensity is stronger for the product prepared by the flux method than for the product prepared by solid state reaction, suggesting that the flux method gives a highly crystalline product.

Figure 3 shows the SEM images of the products prepared by the flux method and solid state reaction. With solid state reaction, $\alpha-\mathrm{BiNbO}_{4}$ particles aggregate and $\beta$-BiNbO 4 particles neck because of long-duration heating at high temperature. In contrast, with the flux method, both $\alpha-\mathrm{BiNbO}_{4}$ and $\beta-\mathrm{BiNbO}_{4}$ particles form euhedral crystals. The difference in behavior and thus product morphology presumably arises as follows: in the solid state, reaction occurs via interparticle contact and proceeds unevenly, whereas in the liquid phase, reaction occurs at the atomic level in solution and proceeds evenly. Moreover, synthesis by the flux method using $\mathrm{Bi}_{2} \mathrm{O}_{3}-\mathrm{B}_{2} \mathrm{O}_{3}$ eutectic flux presumably promotes crystal growth by dissolving $\mathrm{Nb}_{2} \mathrm{O}_{5}$ from the solute. 


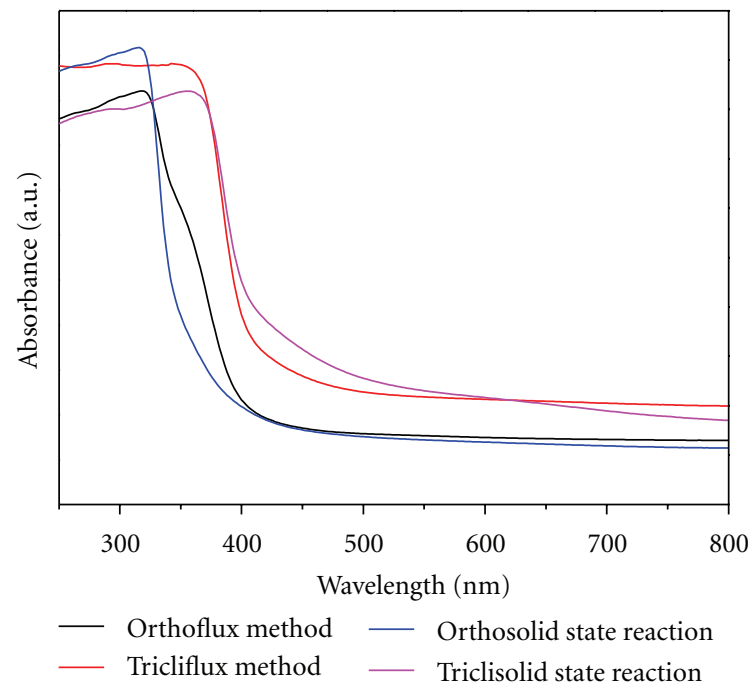

FIGURE 4: UV-Vis diffuse reflectance spectra of $\mathrm{BiNbO}_{4}$ prepared by the flux method and solid state reaction.

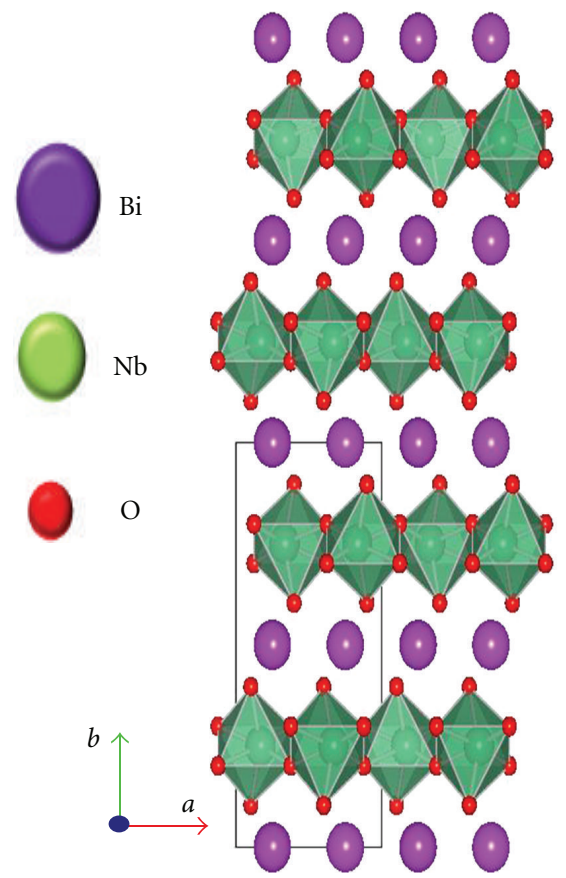

(a)

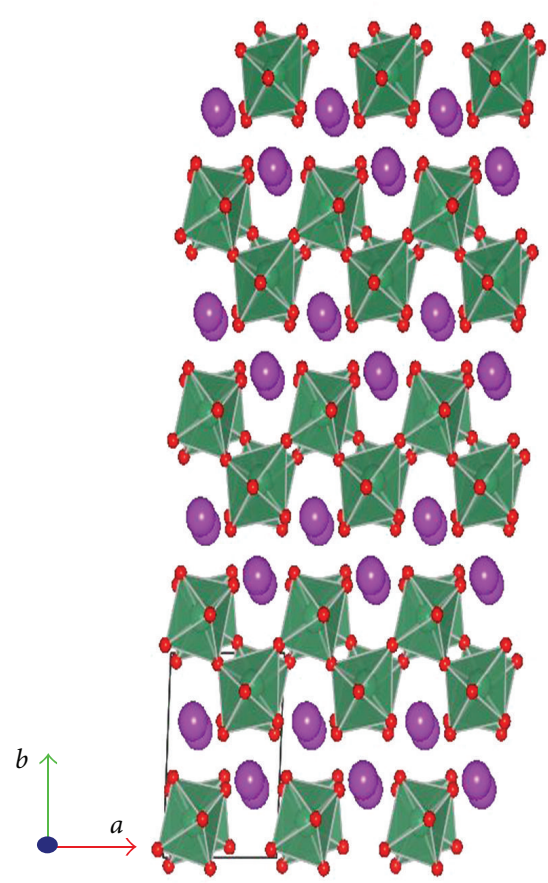

(b)

Figure 5: Crystal structures of $\mathrm{BINbO}_{4}$ : (a) orthorhombic system and (b) triclinic system.

Figure 4 shows UV-Vis diffuse reflectance spectra of the products prepared by the flux method and solid state reaction. The absorption edge is at a longer wavelength for the high-temperature triclinic phase than for the lowtemperature orthorhombic phase, suggesting that the former is available for longer wavelength light than the latter. The difference between the absorption edge for the two phases is due to differences in their crystal structures. The valence band of $\mathrm{BiNbO}_{4}$ is composed of a $\mathrm{Bi} 6 \mathrm{~s}^{2}$ and $\mathrm{O} 2 \mathrm{p}$ hybrid orbital. The conduction band of $\mathrm{BiNbO}_{4}$ is composed of an
$\mathrm{Nb} 4 \mathrm{~d}$ orbital [11]. Wiegel and coworkers have reported that the $\mathrm{Bi} 6 \mathrm{~s}^{2}$ valence band potential for the high-temperature phase lies just above the $\mathrm{O} 2 \mathrm{p}$ valence band potential and that the Bi $6 s^{2}$ valence band potential for the low-temperature phase lies just beneath the $\mathrm{O} 2 \mathrm{p}$ valence band potential [20]. These findings readily explain the observed difference between the absorption edge for the low-temperature and high-temperature phases.

Figure 5 shows the crystal structures of $\mathrm{BiNbO}_{4}$ 's lowtemperature orthorhombic and high-temperature triclinic 
systems. In both systems, $\mathrm{Bi}$ atom layers and $\mathrm{NbO6}$ octahedron layers alternate. In the orthorhombic system, they do so in a flat manner; in the triclinic system, they do so in a zigzag manner. The $\mathrm{Nb}-\mathrm{O}$ bond distances are almost equal in the two systems. However, the cell volumes differ and are larger (about $330 \AA$ ) for the flat-layered orthorhombic system and smaller $(324 \AA)$ for the zigzag-layered triclinic system [19]. The difference of $\mathrm{Bi} 6 \mathrm{~s}^{2}$ valence band potential is considered to differ in cell volume. Moreover, the separation of excited electrons and holes is easier in the flat-layered orthorhombic system than in the zigzag-layered triclinic system. Thus, photocatalytic activity seems to be greater for the orthorhombic system compared with the triclinic system.

\section{Conclusions}

We succeeded in the synthesis of low-temperature-phase $\mathrm{BiNbO}_{4}$ using $\mathrm{Bi}_{2} \mathrm{O}_{3}-\mathrm{B}_{2} \mathrm{O}_{3}$ eutectic flux. The synthesis temperature, $1073 \mathrm{~K}$, is $100 \mathrm{~K}$ lower than that for the synthesis by conventional solid state reaction. Separation of products and flux is accomplished easily by washing with $2 \mathrm{M} \mathrm{HNO}_{3}$ in an ultrasonic bath. Particles so prepared differ from those prepared by solid state reaction in two significant ways: (1) they are highly crystalline and euhedral as opposed to agglutinate and (2) their diffraction intensity is stronger. UVVis diffuse reflectance spectra show that the absorption edge is longer for the high-temperature phase than for the lowtemperature phase of $\mathrm{BiNbO}_{4}$, suggesting that of the two phases, the high-temperature phase is available for longerwavelength light.

\section{References}

[1] A. Fujishima and K. Honda, "Electrochemical photolysis of water at a semiconductor electrode," Nature, vol. 238, no. 5358, pp. 37-38, 1972.

[2] A. Kudo, "Development of photocatalyst materials for water splitting," International Journal of Hydrogen Energy, vol. 31, no. 2, pp. 197-202, 2006.

[3] M. Takeuchi, S. Sakai, A. Ebrahimi, M. Matsuoka, and M. Anpo, "Application of highly functional Ti-oxide-based photocatalysts in clean technologies," Topics in Catalysis, vol. 52, no. 12, pp. 1651-1659, 2009.

[4] R. Shi, J. Lin, Y. Wang, J. Xu, and Y. Zhu, "Visible-light photocatalytic degradation of $\mathrm{BiTaO}_{4}$ photocatalyst and mechanism of photocorrosion suppression," Journal of Physical Chemistry C, vol. 114, no. 14, pp. 6472-6477, 2010.

[5] K. Domen, J. N. Kondo, M. Hara, and T. Takata, "Photo- and mechano-catalytic overall water splitting reactions to form hydrogen and oxygen on heterogeneous catalysts," Bulletin of the Chemical Society of Japan, vol. 73, no. 6, pp. 1307-1331, 2000.

[6] S. S. Dunkle and K. S. Suslick, "Photodegradation of $\mathrm{BiNbO}_{4}$ powder during photocatalytic reactions," Journal of Physical Chemistry C, vol. 113, no. 24, pp. 10341-10345, 2009.

[7] B. Aurivellius, "X-ray investigations on $\mathrm{BiNbO}_{4}, \mathrm{BiTaO}_{4}$ and $\mathrm{BiSbO}_{4}$," Arkiv för Kemi, vol. 3, no. 2-3, pp. 153-161, 1951.

[8] R. S. Roth and J. L. Waring, "Phase equilibrium relations in binary system bismuth sesquioxide-niobium pentoxide," Journal of Research of the National Bureau of Standards Section A-Physics and Chemistry, vol. 66, no. 6, pp. 451-463, 1962.
[9] B. Muktha, J. Darriet, G. Madras, and T. N. Guru Row, "Crystal structures and photocatalysis of the triclinic polymorphs of $\mathrm{BiNbO}_{4}$ and $\mathrm{BiTaO}_{4}$," Journal of Solid State Chemistry, vol. 179, no. 12, pp. 3919-3925, 2006.

[10] Z. Zou, J. Ye, K. Sayama, and H. Arakawa, "Photocatalytic and photophysical properties of a novel series of solid photocatalysts, $\mathrm{BiTa}_{1-x} \mathrm{Nb}_{x} \mathrm{O}_{4}(0 \leq x \leq 1)$," Chemical Physics Letters, vol. 343, no. 3-4, pp. 303-308, 2001.

[11] Z. Zou and H. Arakawa, "Substitution effect of $\mathrm{Ta}^{5+}$ by $\mathrm{Nb}^{5+}$ on photocatalytic, photophysical, and structural properties of $\mathrm{BiTa}_{1-x} \mathrm{Nb}_{x} \mathrm{O}_{4}(0 \leq x \leq 1.0)$," Journal of Materials Research, vol. 17, no. 6, pp. 1446-1454, 2002.

[12] Z. Zou, J. Ye, and H. Arakawa, "Photocatalytic water splitting into $\mathrm{H}_{2}$ and/or $\mathrm{O}_{2}$ under $\mathrm{UV}$ and visible light irradiation with a semiconductor photocatalyst," International Journal of Hydrogen Energy, vol. 28, no. 6, pp. 663-669, 2003.

[13] Z. Zou and H. Arakawa, "Direct water splitting into $\mathrm{H}_{2}$ and $\mathrm{O}_{2}$ under visible light irradiation with a new series of mixed oxide semiconductor photocatalysts," Journal of Photochemistry and Photobiology A, vol. 158, no. 2-3, pp. 145-162, 2003.

[14] C. Y. Lee, R. Macquart, Q. Zhou, and B. J. Kennedy, "Structural and spectroscopic studies of $\mathrm{BiTa}_{1-x} \mathrm{Nb}_{x} \mathrm{O}_{4}$," Journal of Solid State Chemistry, vol. 174, no. 2, pp. 310-318, 2003.

[15] D. Chen and J. Ye, "Selective-synthesis of high-performance single-crystalline $\mathrm{Sr}_{2} \mathrm{Nb}_{2} \mathrm{O}_{7}$ nanoribbon and $\mathrm{SrNb}_{2} \mathrm{O}_{6}$ nanorod photocatalysts," Chemistry of Materials, vol. 21, no. 11, pp. 2327-2333, 2009.

[16] D. Arney, B. Porter, B. Greve, and P. A. Maggard, "New molten-salt synthesis and photocatalytic properties of $\mathrm{La}_{2} \mathrm{Ti}_{2} \mathrm{O}_{2}$ particles," Journal of Photochemistry and Photobiology A, vol. 199, no. 2-3, pp. 230-235, 2008.

[17] M. A. Subramanian and J. C. Calabrese, "Crystal structure of the low temperature form of bismuth niobium oxide $[\alpha$ $\mathrm{BiNbO}_{4}$ ]," Materials Research Bulletin, vol. 28, no. 6, pp. 523529, 1993.

[18] E. M. Levin and C. L. McDaniel, "The system $\mathrm{Bi}_{2} \mathrm{O}_{3}-\mathrm{B}_{2} \mathrm{O}_{3}$," Journal of the American Ceramic Society, vol. 45, no. 8, pp. 355360, 1962.

[19] E. T. Keve and A. C. Skapski, "The crystal structure of triclinic $\beta$-BiNbO ${ }_{4}$," Journal of Solid State Chemistry, vol. 8, no. 2, pp. 159-165, 1973.

[20] M. Wiegel, W. Middel, and G. Blasse, "Influence of $n s^{2}$ ions on the luminescence of niobates and tantalates," Journal of Materials Chemistry, vol. 5, no. 7, pp. 981-983, 1995. 

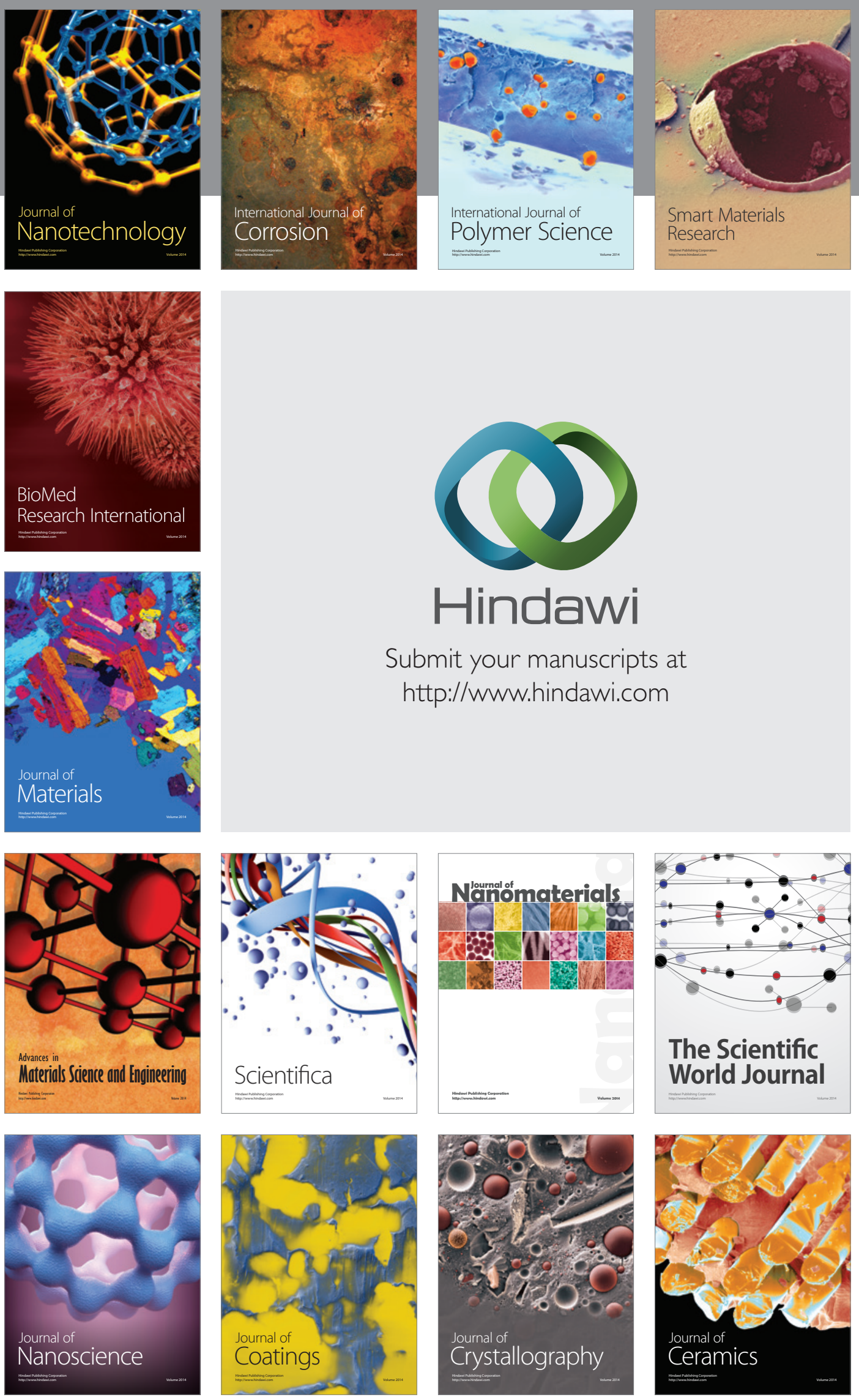

The Scientific World Journal

Submit your manuscripts at

http://www.hindawi.com

\section{World Journal}

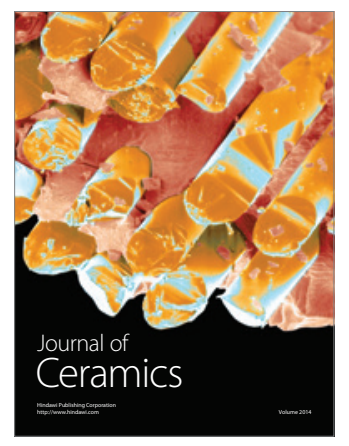

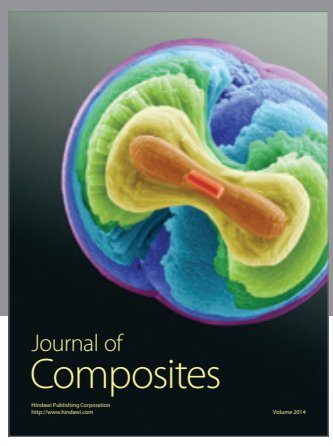
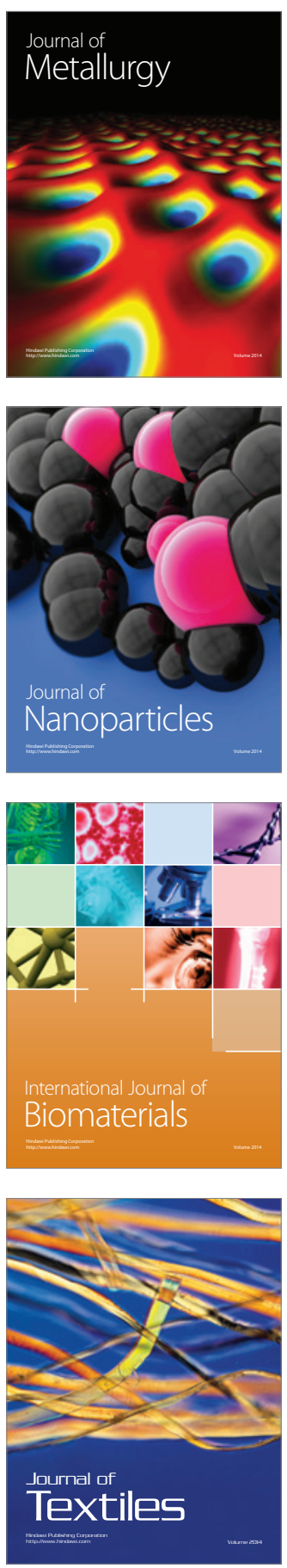